\title{
VERIFICATION OF SHRINKAGE FORMATION IN STEEL INGOTS IN LABORATORY CONDITIONS
}

The paper describes the process of ingot casting from a modelling material into a special ingot mould made for these tests. As a modelling material we chose stearin (tristearin, glycerol tristearate), which proved to be suitable for this kind of laboratory tests. Casting was done in two ways - using a vertical ingot mould and a horizontal one. Observation of the ingot after solidification confirmed the fact that the cavity filling took place in the laminar flow of the melt.

Keywords: Ingot, forging, shrinkage, modelling material, crack, casting.

\section{Introduction}

In technological practice we constantly search for methods and ways that can ensure comparably usable parameters for a real process, obtained in experiments.

The following text focuses on one of the several ways enabling shrinkage formation in the body of the ingot, and also on the study of the shrinkage process using modelling materials.

For quite a long time experimental work has been done using easily meltable materials $[1-4]$

\section{Ingot casting - practical aspects}

In terms of the theory of solidification and crystallisation, the most preferred way is casting of dimensionally smallest ingots. This is used when the aim is to achieve optimal homogeneity - both chemical and structural. Practical manufacture of steel ingots is a challenging technical and organisational process and a problem depending on several factors, such as:

1) basic type of cast steel (killed and rimmed steel),

2) required shape of the ingot for further processing,

3) chemical composition of the material,

4) size of the production unit,

5) cycle of ingot mould set preparation,

6) method of ingot casting (bottom, top),

7) number of ingot types,

8) production capacity of the forge.
Methods of experimental research into the solidification process are divided into direct and indirect.

\section{Direct methods:}

- discharge of liquid metal from the ingot mould, and measuring the thickness of the remaining solidified melt,

- monitoring the solidification process by means of a bar immersed in the liquid steel at a certain angle (bar test),

- dipping a mandrel into the steel.

\section{Indirect methods:}

- measurement of the steel temperature using thermocouples,

- addition of trace elements or radioisotopes to the liquid steel,

- disturbance of steel crystallisation by mechanical effects (shock, vibration),

- modelling using low-melting compounds.

Of great importance for good formability (malleability, ductility) is the size and arrangement of crystals and segregates in ingots, which are influenced by the number of crystal nuclei and rate (velocity) of crystallisation, as well as by the volume change in the melt's transition into a solid state [5].

The most commonly used ingot for forges is an ingot with a wider top end. In case of small ingots, solidification occurs simultaneously in the whole cross-section of the part of the ingot in the ingot mould. Although dendritic segregation can be detected in these ingots, but the chemical composition is uniform all over the cross-section. Hardly any differences are manifested

\footnotetext{
* ${ }^{1}$ Jan Moravec, ${ }^{2}$ Jan Langa, ${ }^{3}$ Pavel Solfronk

${ }^{1}$ Department of Technological Engineering, Faculty of Mechanical Engineering, University of Zilina, Slovakia ${ }^{2}$ ROSS , Ltd. Rajec, Slovakia

${ }^{3}$ Department of Productive Engineering, Faculty of Mechanical Engineering, Technical University of Liberec, Czech Republic E-mail: jan.moravec@fstroj.uniza.sk
} 
in the content of individual elements between the surface and the centre. There are only a few differences between the top and bottom parts of the ingot. A large ingot (Fig. 1) of fully killed steel features various regions corresponding to the course of crystallisation.

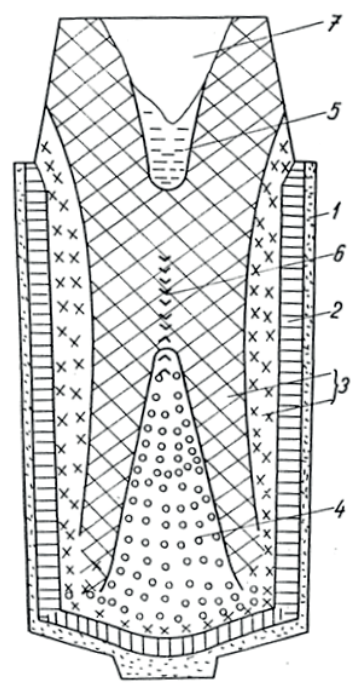

Fig. 1 Scheme of the structure in the ingot

Area 1Thinouterlayeroffine, veryclearpolyedricalgrains;Area 2 Collumnary long-axis, still very clear crystals; Area 3 Thick polyedrical grains; Area 4 Globular grains transformed into pyramid shape in bottom part of ingot; Area 5 Small zone just under the head of ingot;Area 6 Minimal homogenity; Area 7 Head of ingot with shrinkage

\section{Faults of steel ingots}

Main shrinkage. In case of ingots with lost tops, the main shrinkage must remain in the ingot top. When it appears in the ingot body, it is the result of an undercast or too-little ingot top.

Shrinkage porosities are caused by insufficient refilling of liquid steel.

Total porosity is the result of insufficient deoxidation.

Distinctive dendritic segregation occurs due to a too high crystallisation rate at a small number of crystallisation nuclei.

Longitudinal cracks on the walls are the result of stress at too fast hot casting, or at premature removal of the ingot from the ingot mould and its rapid cooling.

Transverse and diagonal cracks are caused by obstacles in the shrinkage of the ingot - either by the ingot mould or by unsuitable casting temperature and rate.

\section{Experimental work}

The experiments were performed in the forming technology laboratory of the Department of Technological Engineering, Faculty of Mechanical Engineering, University of Zilina, Slovakia. As modelling material we used pure crystalline sodium thiosulphate pentahydrate - $\mathrm{Na}_{2} \mathrm{~S}_{2} \mathrm{O}_{3} .5 \mathrm{H}_{2} \mathrm{O}$. The experiments were conducted in the chemical laboratory of the Department of Technological Engineering, Faculty of Mechanical Engineering, University of Zilina, Slovakia. Thiosulphate melted at a temperature from 52 to $56{ }^{\circ} \mathrm{C}$. We cast into a model ingot mould made of plexiglass (PMMA - poly(methyl methacrylate).

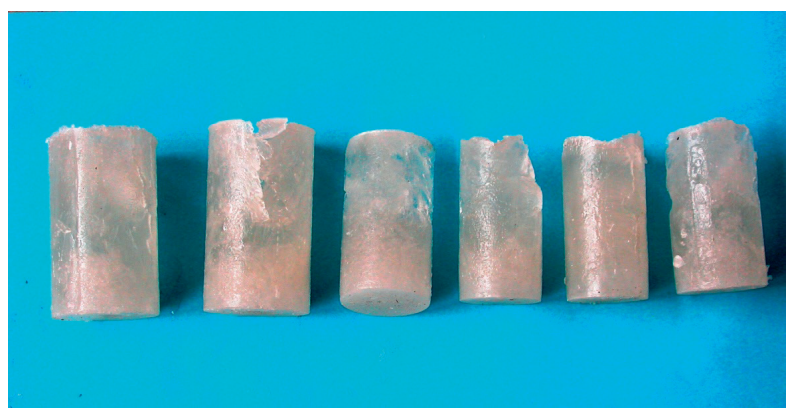

Fig. 2 Samples after casting

Sodium thiosulphate is recommended by KIESEL. L. SMUIN, K. - PABST, W. in Freiberger Forschungshefte 6, B137 [6, pp. 79-92]. They indicate the material melting point as $50{ }^{\circ} \mathrm{C}$.

The applied material in the experiments proved not to be suitable for this type of tests (Fig. 2). It is problematic in terms of removing the samples that stick to the walls despite we coated the cavity surface with a silicon paste film.

\subsection{Using stearin}

The second experimental material we used was stearin. It is a mixture of free fatty acids, in particular palmitic and stearic acids. Synonyms: acidum stearinum, acidum stearin. The melting point is indicated as $55-59{ }^{\circ} \mathrm{C}$. We used a steel ingot mould and

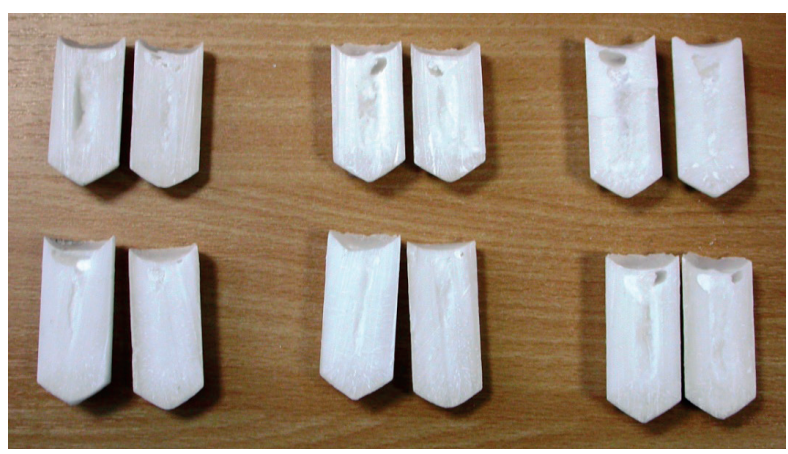

Fig. 3 Shrinkages and cavities in the samples 
cast experimental rollers. These were monitored just like in the previous experiment with sodium thiosulphate.

When applying stearin, differences became apparent in the quality of the cast samples. The bodies of samples after solidification in the ingot mould were relatively suitable for subsequent observations. Figure 3 shows the samples after completion of the experiment. On Fig. 3 the samples in the upper row and the sample in the bottom right corner were cast at higher temperature. Remaining two samples confirm the data from specialised literature.

\subsection{Model equipment}

According to Fig. 4 we manufactured a model ingot mould shown in Fig. 5. We used this ingot mould to carry out experimental work. Sensor wires were sealed using a sealing paste.

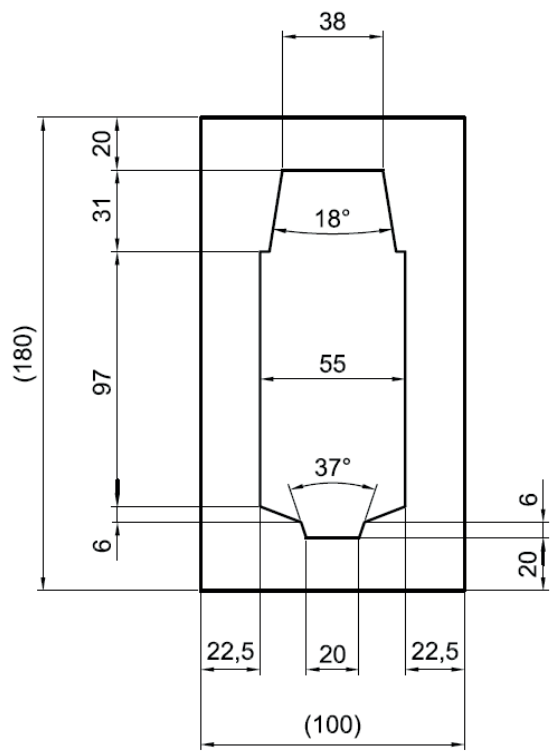

Fig. 4 Drawing of the ingot mould

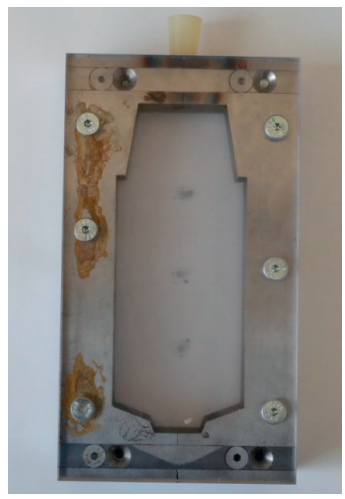

Fig. 5 Ingot mould
To record the temperature we used three sensors at different heights. Values were read from each sensor at pre-defined time intervals. The values were then processed in a chart. We used ALMENO 2890-9 Ahlbonn measuring station. A bad casting was produced at a high melting temperature, but the result was better at a lower temperature. Optimum temperature proved to be $58{ }^{\circ} \mathrm{C}$, when the cavity filling was best. Casting conditions turned much worse when overheating the melt.

\subsection{Filling the ingot mould cavity}

We used silicon oil as a separating layer to separate the melt from the ingot mould wall. Silicon oil reliably accomplished the task. Figs. 7 to 9 thoroughly illustrate the whole course of the process and provide a good overview of all monitored parameters. We carried out two methods of filling the ingot mould cavity: First Case (Fig. 6) status I, and Second Case (Fig. 6) status II. The filling port (inlet), which is not used in either method, is plugged with an auxiliary plug during filling the ingot mould cavity. In the actual cavity filling process we attempted to create the conditions for a linear flow of the melt. Observation of the ingot after it solidified confirmed the fact that the cavity filling was carried out under such conditions in terms of the melt flow velocity. The total time of the cavity filling was $42 \mathrm{~s}$.

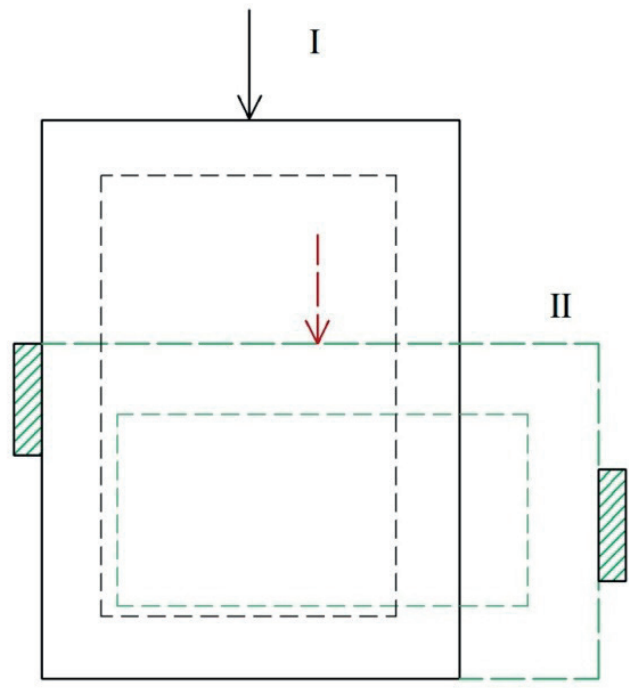

Fig. 6 Two positions for casting ingot

\subsection{The course of experimental work}

In this paragraph we publish images of the course of solidification of the model ingot during experimentation in two positions: in the vertical axis and in the transverse axis. 

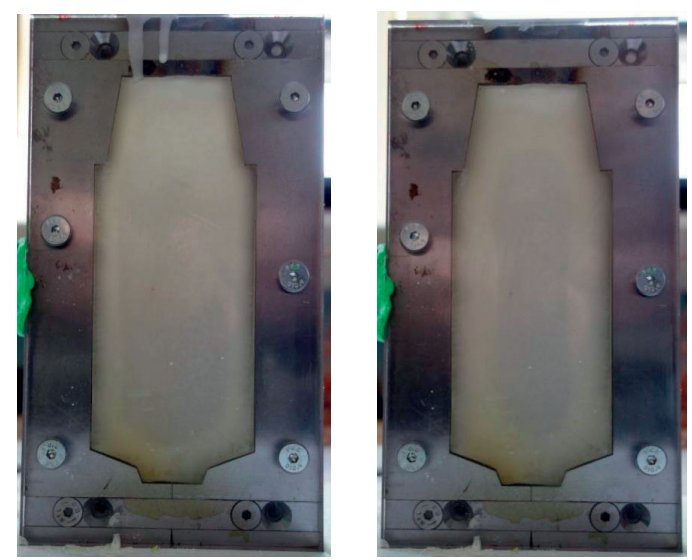

Fig. 7 Solidification of the model ingot in the longitudinal axis: left: after 20 minutes, right: after 40 minutes
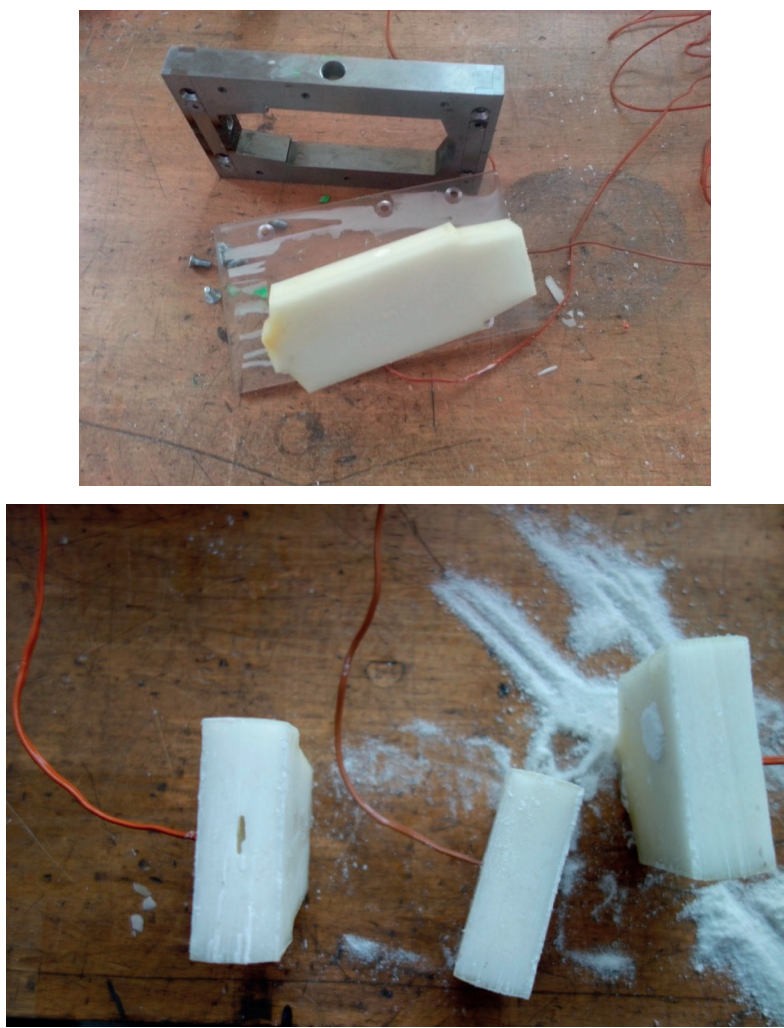

Fig. 8 Sample after removal from the ingot mould and slicing

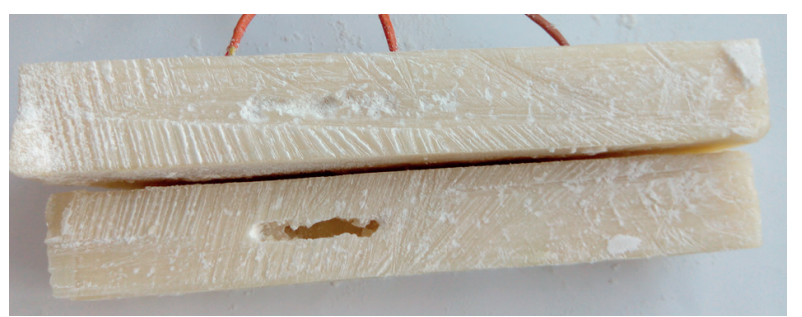

Fig. 9 Shrinkages and cavities in the samples
In the course of the model ingot solidification process in laboratory conditions we observed how a layer was gradually forming along the contour of the ingot casting. Cooling of the ingot was gradual, which resulted in reducing the volume of liquid phase in the ingot body, which was observed during the experiment. Shrinkage is readily observable with the naked eye, and this is manifested by formation of a gap between the ingot mould wall and the ingot body. Based on the temperature readings of the thermocouples we plotted a graph - dependance of temperature on time during the ingot cooling. The temperature of the ingot decreased rapidly during the first five minutes, then it stabilised at the same value (see Fig. 10).

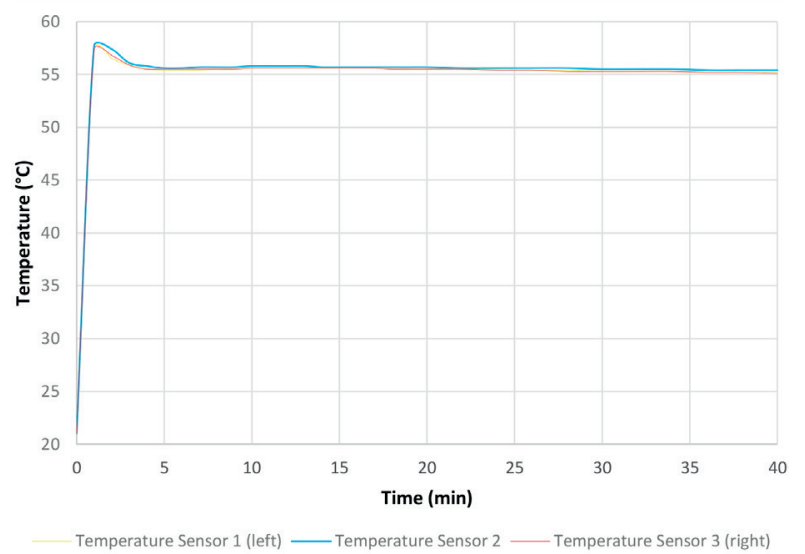

Fig. 10 Graphs showing temperatures over the sample solidification

\subsection{Solidification}

Regarding solidification it is desirable to continue to determine the effect of chemical composition of steels (high carbon and high alloyed steels) on the liquidus and solidus temperatures. It is also necessary to deal with the determination of the coefficients of heat transfer between the ingot and the mould, and between the ingot and the pad, both for conventional casting as well as for continuous casting. The above-mentioned data are required for a very close approximation of numerical procedures to real-life conditions during cooling of steel ingots. Special attention should be paid to the study of solidification of very heavy ingots of non-alloyed as well as alloyed steels, because other properties of forgings are largely influenced by solidification and primary crystallisation of ingots. The solidification process is directly associated with the development of macro-segregations, segregates and sedimentation cone. Heavy forgings are the basis for the development of mechanical engineering and chemistry. It is also equally important to study solidification of the ingot surface layer in order to comprehensively improve surface quality of raw ingots and prevent cracks resulting from heat stress [6 - 7]. 


\subsubsection{Steel shrinkage during cooling and solidification}

Shrinkage in ingots is formed due to steel shrinking during its cooling and solidification. The size of shrinkage can be calculated using the equation by [8]:

$V_{S}=\alpha_{V}+\alpha_{\Delta t}\left(t_{1}-t_{S}\right)-\frac{1}{2} \beta\left(t_{S}-t_{2}\right)$

where $V_{S}$ is the volume of shrinkage,

$\alpha_{\mathrm{v}}-$ the coefficient of volumetric shrinkage during solidification (dimensionless),

$\beta$ - the coefficient of volumetric shrinkage in the solid state,

$t_{-}$- the mean temperature of liquid steel at the beginning of solidification,

$t_{2}$ - the mean temperature of solidified steel at the end of solidification,

$t_{s}$ - the solidification temperature,

$a \Delta_{t}$ - the coefficient of volumetric shrinkage in the liquid state.

Shrinkage size when casting steel into an ingot mould, if $\alpha_{V}=0.0034, \alpha_{\Delta t}=0.9 \cdot 10^{-4} K^{-1}, \beta=0.64 \cdot 10^{-4} K^{-1}$,

$t_{1}=1525^{\circ} \mathrm{C}, t_{2}=1275^{\circ} \mathrm{C}, t_{S}=1500{ }^{\circ} \mathrm{C}$.

$V_{S}=0.034+0.9 \cdot 10^{-4}(1525-1500)-$

$-\frac{1}{2} \cdot 0.64 \cdot 10^{-4}(1500-1275)$

$V_{S}=0.034+2.25 \cdot 10^{-3}-7.2 \cdot 10^{-3}$

$V_{S}=0.029$

The shrinkage volume is $2.9 \%$ of the ingot volume.

The equation does not include metal solidification during casting, which is of particular importance in ingot casting. The shrinkage size is governed by the relation by [9]:

$V_{S}=\alpha_{4 t}\left(t_{1}-t_{S}\right)+\alpha_{v} \eta-\beta\left(t_{1}-t_{2}\right) \varphi-\beta\left(t_{S}-t_{2}\right) \eta$

where: $(1-\eta)$ is the ratio of the amount of metal solidified during casting, $\varphi$ - is the coefficient of deformation of solidified crust due to ferrostatic pressure, $t_{1}-$ is the ingot surface temperature at the end of casting, $t_{2}-$ is the temperature of the ingot at the end of solidification.

The above-mentioned relationship not only includes steel solidification during casting, but it also notes the solidified crust deformation. Differences in the shrinkage volumes can be explained in case of ingots of different sizes by the solidified crust deformation. However, accurate representation of the third member of the equation is difficult. According to [10] the equation was modified by taking into account the proportion of steel solidified during casting, leading to the following equation:

$V_{S}=\alpha_{V}+\alpha_{\Delta t}\left(t_{1}-t_{S}\right)-0.5 \beta\left(t_{S}-t_{2}\right) \frac{V_{i+h}-\vartheta_{1}}{V_{i+h}}$ where: $V_{i}$ - is the volume of ingot body, $\vartheta_{1}$ - thermal flow.

\subsubsection{Vertical solidification of the ingot}

Solidification of the ingot from the bottom in the vertical direction affects the central uniformity of the steel. A theoretical calculation of the course of vertical solidification of a cylindrical ingot according to equation (4) [11] (see Fig. 11):

$$
h=\frac{r}{2} \ln \frac{r}{r-2 k \sqrt{\tau}}
$$

Derivation of equation 4 is based on the following simplifying assumption:

1. the ingot pad is a flat plate,

2. the heat removed in vertical and horizontal directions is calculated according to a parabolic relationship, $\xi=\mathrm{k} \tau$

$Q=\frac{k}{n} \sqrt{(t)} \pi r^{2}$

where $n$ is an empirical coefficient $\left(\mathrm{m}^{3} \mathrm{~J}^{-1}\right), k$ - is constant of solidification.the volume of solidified metal for the time period $\mathrm{d} \tau$ is directly proportional to the amount of heat removed for the same time period:

$$
\begin{aligned}
& \frac{d V}{d \tau}=n \frac{d Q}{d \tau} \\
& d V=\left(\pi r^{2}-2 \pi r \xi\right) d h \\
& \frac{d V}{d \tau}=\left(\pi r^{2}-2 \pi r \xi\right) \frac{d h}{d \tau}
\end{aligned}
$$

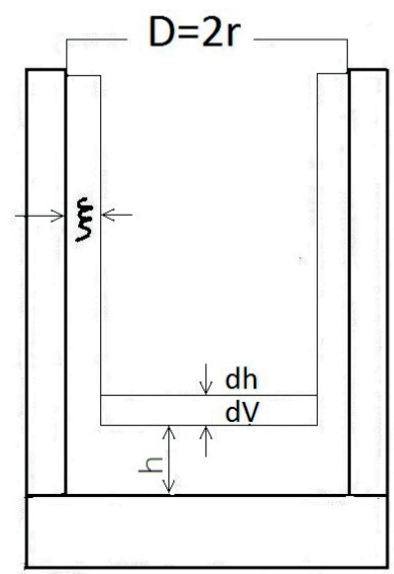

Fig. 11 Scheme of a solidifying ingot with designated individual parameters used in the equation

The resulting equations (6), (7a) and (7b) is as follows: $\frac{d Q}{d \tau}=\frac{1}{2} \frac{k}{\sqrt{\tau}} \frac{\pi r^{2}}{n}$ 
$\frac{\mathrm{dh}}{\mathrm{d} \tau}=\frac{\mathrm{kr}^{2}}{2\left(r^{2} \sqrt{(\tau)}-2 r k \tau\right)}$

and after integration and determination of the integration constant from the condition ( $t=0$ is $h=0$ ), the resulting equation

(4) $: h=\frac{r}{2} \ln \frac{r}{r-2 k \sqrt{\tau}}$

Difference between the predefined course of vertical solidification according to the probe measurements and the theoretical calculation using equation (4) is determined by sedimentation of equiaxed crystals, which is not taken into account in equation (4).

\section{Discussion}

\subsection{Mechanism of shrinkage formation}

Shrinkage formation can be explained using Fig. 12, which represents an axial section of a cast solid cylinder without a raiser (stages a to d) and a solid cylinder with a raiser (Fig. 12e).

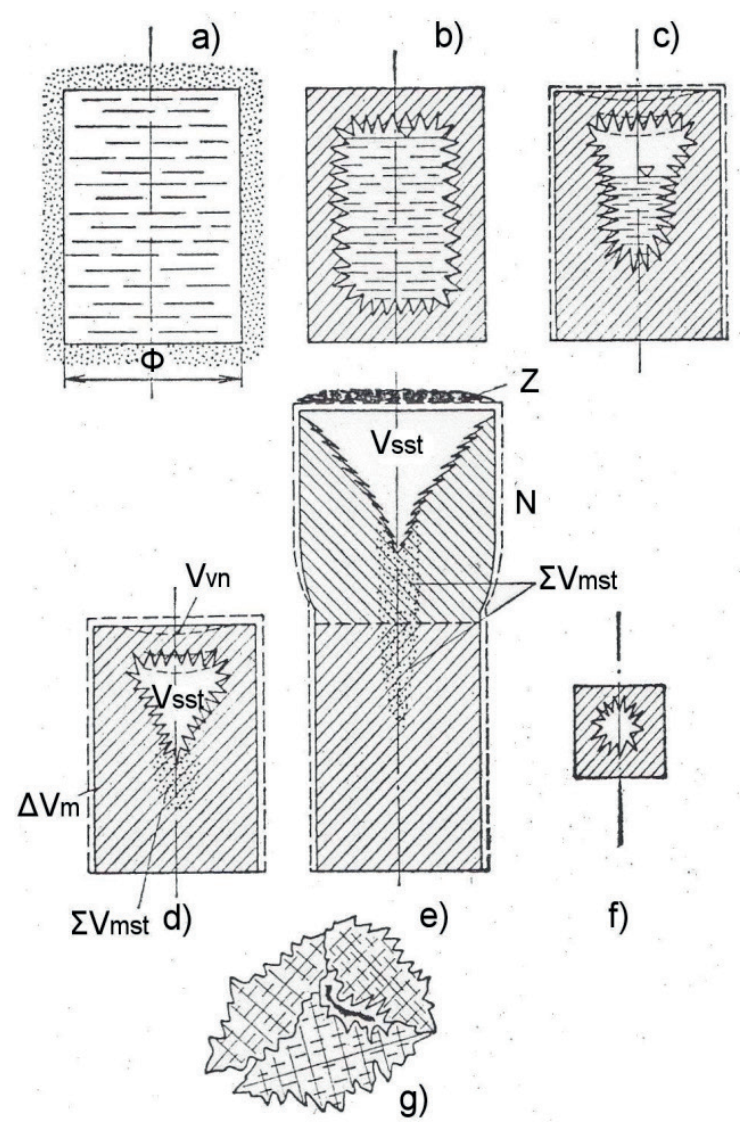

Fig. 12 Mechanism of volume shrinkage progression
Stage a: It captures the situation at the time casting: the mould cavity is filled with the melt.

Stage $b$ : The melt cools down from the mould, therefore solidified crust has already formed near the casting surface, and the crust interior contains the melt. We observe the arising manifestation of predominance of volume loss $\Delta V_{I}+\Delta V_{I I}$ over $\Delta V_{I I I}$, therefore the melt layer on top is separated from the upper solidified crust.

Stage c: Thickness of the upper crust does not increase, but it keeps increasing at the point of contact of the crust with the melt. Inconsistency between $\Delta V_{I}+\Delta V_{I I}$ on the one hand, and $\Delta V_{I I I}$ on the other hand deepens, therefore the cavity has a larger volume. The upper horizontal, and still glowing, crust is affected by negative pressure from inside and atmospheric pressure from outside, therefore the crust can fold inwards.

Stage $d$ : End of shrinkage growth. The melt disappeared, a cavity - shrinkage remains in the body. The casting outer clearance is noticeably reduced compared to the initial melt volume poured in. It should be noted that the total shrinkage volume $V_{s t}$ should be distinguished from the volume of concentred shrinkage or macro-shrinkage $V_{s s}$, from the volume of outer shrinkage $V_{v n}$, and from the totalised volume of dispersed shrinkage porosity $\Sigma$ $V_{m s t}$ that is formed in a certain region under the shrinkage. The following applies:

$V_{s t}=V_{s s t}+V_{v n}+\sum V_{m s t}$

To avoid shrinkage formation in the casting, we attach to the casting a riser $N$ with a certain amount of the melt and a modulus greater than that of the casting (Fig. 12e). Thus, we cast the casting with the raiser, and the metal level in the raiser is topped with an exothermic agent, so that it could remain liquid as long as possible ("non-solidifying level"). Concentred shrinkage $V_{\text {stt }}$ is then formed in the raiser, and below it there is a region experiencing shrinkage porosity $\Sigma V_{m s t}$

The shrinkage position in the upper part of the cast body is the result of the action of gravity, which affects the melt displacement during solidification and shrinkage. Its effect is predominant in the case of the melt macro-volume. In that case the effect of capillary forces recedes.

\subsection{Essence of crack formation}

\section{Free material shrinking}

Immediately from its creation, the solid phase of steel decreases its volume during cooling, and its tiny pre-shrinking expansion is actually of no significance. The course of alloy shrinking from casting to cooling can be determined using a foundry dilatometer. This test monitors the shortening of a cast test bar, and provides the following dependencies: $t-\tau$ (bar 
temperature change with time) and $\Delta l-\tau$ (bar gauge length change with time). Using these dependencies we can create the dependency $t-\Delta l$.

The dependency $t-\Delta l$ in carbon steels with different $\mathrm{C}$ content varies. Each temperature corresponds to a certain free length of the bar (i.e. without stress). Using this dependency we can create the dependencies $t-\tau t$ and $\Delta l-\tau$.

Length of the bar in molten state is $l$. At the selected time $\tau_{l}$, the difference in the length of the bar free and decelerated shrinking is $l_{b}-l_{v}$, i.e. $\Delta l_{b}-\Delta l_{v}$. From this difference we must deduct the corresponding plastic elongation (ductility) of the bar $\Delta l_{p}$ at the time $\tau_{l}$

The general equation for tensile shrinking stress (exogenous) $\sigma_{t}$ can be written as follows:

$\sigma_{t}=\frac{l_{b}-l_{v}-\Delta l_{p}}{l} \cdot \frac{\Delta l_{v}-\Delta l_{b}-\Delta l_{p}}{l} \cdot E$

where $E$ is the modulus of elasticity at a corresponding temperature. The unconventionally expressed numerator takes into account the proportion of elastic $\left(l_{p}-l_{v}\right)$ and plastic $\left(\Delta l_{p}\right)$ deformations. It follows from the equation that the greater $\Delta l$, is, the more the value of stress is reduced. When $l_{b}-l_{v}-\Delta l_{p}=0$, the resulting stress is zero and the curve $c$ is identical to the curve $b$. From the thermal point of view, the following applies: $\varepsilon=\alpha \cdot \Delta t$ where $\varepsilon$ is the relative elastic elongation:

$\varepsilon=\frac{l_{b}-l_{v}}{l}$

$\alpha$ - temperature coefficient of linear expansion,

$\Delta t$ - temperature difference (expresses non-homogeneity of the temperature field).

Substituting these two values into equation (9) gives:

$\sigma_{t}=\left(\alpha \cdot \Delta t-\frac{\Delta l_{p}}{l}\right)$

The equation is suitable for the determination of inherent stresses. Modulus of elasticity $E$ in the two equations is problematic because its value cannot be determined for solidus, it can only be very roughly assumed. Nevertheless, these equations provide an idea of the quantitative aspect of stress.

Figure 13 shows the course of cracks in relation to the direction of tensile stress.

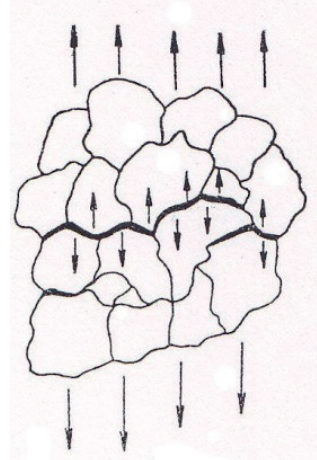

a)

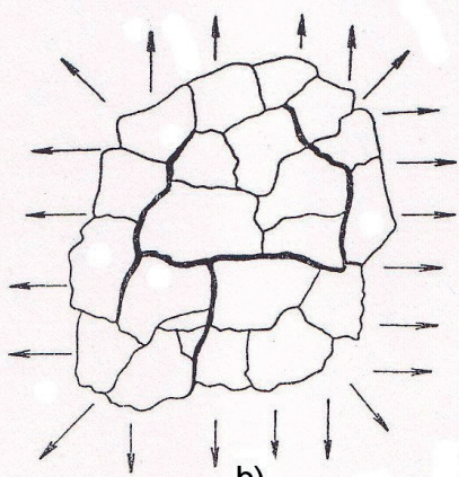

b)
Fig. 13 The course of cracks in relation to the direction of tensile stress

\section{Conclusion}

Kiesel [11] utilised model experiments on ingots with sodium thiosulphate, cast into ingot moulds made of plexiglass, to observe the effect of the ingot mould conicity and slenderness on the course of vertical solidification. An increase in conicity for $45 \mathrm{t}$ forging ingots very significantly improved homogeneity in the axial part, as well as a reduction in the H/D ratio, because vertical solidification significantly slowed. When we look at the curve depicting the vertical solidification process with respect to time, we can conclude that the smaller the curve slope, the better ingot homogeneity in the axial part. Acceleration of vertical solidification in the later stages of the ingot solidification can be explained by the horizontal solidification fronts getting closer to the ingot axis. Efficient and long-term heating of the ingot top (by electric arc or induction) may affect the central part of the ingot by slowing down vertical solidification. Input power must be regulated so that, at the time of the ingot solidification, too intense heating does not result in the creation of a wide two-phase zone of solidification in the ingot axis [12].

This paper described the process of ingot solidification in a model ingot mould when placing the given mould in two positions. The graphs show the course of temperatures recorded by three sensors during 40 minutes. At the stearin casting temperature of $58{ }^{\circ} \mathrm{C}$ we can observe that inner shrinkage is smaller. Shrinkage could be completely eliminated using a raiser. Material to forming (forging) processes is supplied in the form of castings, i.e. this is what forming inherently affects. Therefore, it is necessary to deal with this phenomenon that, as soon as at its initial input (first entry), affects the resulting quality of shaped parts.

\section{Acknowledgement}

The article was created in frame of VEGA 1/0077/15. 


\section{COMMNICOIIONS}

\section{References}

[1] SMRHA, L.: Crystalization and Solidification of Steel Ingots, Praha: STNL, 1983.

[2] SMRHA, L.: CHVOJKA, J.: Foundry Letters, 63/9.

[3] SMRHA, L.: Foundry, 1962, No. 10, 245-249.

[4] JAMES, W., MIDDLETON, R.: British Foundryman, January 58, 36-46.

[5] PRIBYL, J.: Controlled Solidification of Steel Castings, Praha: STNL, 1986.

[6] SMRHA, L., CHVOJKA, J.: Foundry Letters, 63/9.

[7] KIESEL. L., SMUIN, K., PABST, W.: Freiberger Forschungshefte, 6, B137, 79-92.

[8] CHVORINOV, N. : Giesserei, No. 10, 177-186, No. 11, 201-208, 1975.

[9] NECHENEDZI, JU.: Foundry Production (in Russian), No. 3, 14-19, Moskva 1982.

[10] GULJAJEV, B. B.: Solidification and Heterogenity Steel (in Russian), Metallurgizdat, Moskva, 1986.

[11] KIESEL. L., SMUIN, K., PABST, W.: Freiberger Forschungshefte, 5, B137, 81-93.

[12] MORAVEC, J.: Cutting Metal Sheet with a Punch with Interal Heating, Communications - Scientific Letters of the University of Zilina, 2016, ISS 1335-4205. 